\title{
Modeling approach to the elements of TQM practice
}

\begin{abstract}
This paper considers three factors; the selection of the Performance Measures, selection of the Critical Success Factors, and selection of quality tools as three elements of TQM. The qualitative research of this study tries to find and model the interrelation between elements of Total Quality Management (TQM) practice in companies.
\end{abstract}

Keyword: CSF; PM; QT; TQM 